\title{
Implementasi Penguat Lock-in Digital untuk Deteksi Gas
}

\author{
Diana Rofiqoh, Muhammad Rivai, dan Fajar Budiman \\ Departemen Teknik Elektro, Fakultas Teknologi Elektro, \\ Institut Teknologi Sepuluh Nopember \\ e-mail:muhammad_rivai@ee.its.ac.id
}

\begin{abstract}
Abstrak - Pada sebuah pengukuran seringkali dibutuhkan pemulihan sinyal sensor yang kecil yang terbenam dalam sinyal derau. Penelitian ini merancang dan membuat penguat lock-in digital yang berbasis komputer untuk mengolah sinyal yang berasal dari sensor gas karbon monoksida. Mikrokontroler Arduino Mega2560 digunakan sebagai penerima data sensor dan mengirimkannya ke komputer. Seluruh proses utama dalam sistem penguat lock-in digital, seperti proses mixing dan penyaringan yang menggunakan low pass filter dilakukan secara digital. Hasil pengujian menunjukkan bahwa penguat lock-in digital ini dapat meningkatkan nilai Signal-to-Noise Ratio dari sensor gas karbon monoksida sebesar $12 \mathrm{~dB}$.
\end{abstract}

Kata Kunci-Arduino Mega2560, Penguat Lock-in Digital, Sensor gas.

\section{PENDAHULUAN}

$\mathrm{P}$ EMULIHAN sinyal secara optimal dari pengaruh derau merupakan masalah yang sering dijumpai dibidang elektronika dan masih menjadi salah satu fokus dari beberapa penelitian. Hasil pengukuran sensor mengalami penurunan diakibatkan oleh derau. Secara teori, sinyal keluaran yang berasal dari tranduser resistif memiliki derau yang sulit untuk dihilangkan. Derau yang dapat diminimalisir hampir selalu terdapat pada keluaran transduser. Dengan demikian maka menguatkan sinyal yang tercampur derau tidak membuat sinyal asli terbebas dari derau. Pengukuran sinyal elektrik yang memiliki amplitude rendah yang disebabkan oleh suplai tegangan yang rendah, merupakan hal yang sulit dilakukan. Hal ini disebabkan oleh interferensi derau yang tinggi. Salah satu teknik yang digunakan untuk mengembalikan sinyal yang diinginkan adalah dengan phase sensitive (lock-in) detection [1].

Perancangan penguat lock-in secara digital dilakukan karena respon filter yang didapatkan pada penguat lock in digital lebih mendekati ideal dibandingkan dengan penguat lock-in analog. Pada penguat lock-in analog, untuk mendapatkan respon filter yang ideal membutuhkan banyak sekali rangkaian. Semakin besar orde filter maka semakin banyak pula rangkaian analog yang diperlukan. Penguat lock-in digital memiliki fisik yang jauh lebih sederhana karena semua proses dilakukan secara digital. Selain itu pada penguat lock-in digital, sinyal keluaran lebih stabil atau tidak memiliki arus drift dan atau dc couple seperti pada analog serta memiliki akurasi sudut yang lebih akurat dibandingkan dengan rangkaian penguat lock-in analog [2].

\section{TEORI PENUNJANG}

\section{A. Sensor Gas Semikonduktor}

Sensor gas berfungsi untuk mengukur senyawa gas polutan yang ada di udara seperti karbon monoksida, hidrokarbon, nitrooksida, dan lain-lain. Elemen sensor menggunakan bahanbahan seperti timah oksida $\mathrm{SnO}_{2}$, wolfram oksida $\mathrm{WO}_{3}$, dan lainnya, tergantung pada gas yang hendak dideteksi [3]. Prinsip kerja dari sensor ini, semakin tinggi kosentrasi gas maka resistansinya semakin rendah. Gas oksigen yang ada di sekitar permukaan luar kristal akan tertarik oleh muatan negative permukaan luar kristal, sehingga menghambat laju aliran electron [4].

Dalam lingkungan adanya gas pereduksi, kerapatan oksigen teradsorpsi yang bermuatan negatif pada permukaan semikonduktor sensor menjadi berkurang, sehingga ketinggian penghalang pada batas antar butir berkurang. Ketinggian penghalang yang berkurang menyebabkan berkurangnya tahanan sensor butir dalam lingkungan gas [5].

\section{B. Sensor Gas $M Q-7$}

MQ-7 merupakan sensor gas yang digunakan dalam peralatan untuk mendeteksi gas karbon monoksida (CO) dalam kehidupan sehari-hari, industri, atau mobil. Fitur dari sensor gas MQ-7 ini adalah mempunyai sensitivitas yang tinggi terhadap $\mathrm{CO}$, stabil, dan berumur panjang. Sensor ini menggunakan catu daya heater dan rangkaian sebesar 5V DC, kisaran pengukuran konsentrasi gas adalah 20-2000 ppm [6].

\section{Penguat lock-in}

Secara umum diagram penguat lock-in ditunjukkan pada Gambar 1. Sinyal input dimodulasi dengan sinyal referensi yang merupakan keluaran dari osilator. Kemudian penguat lock-in hanya merespon pada sinyal yang memiliki frekuensi yang sama dengan sinyal referensi.

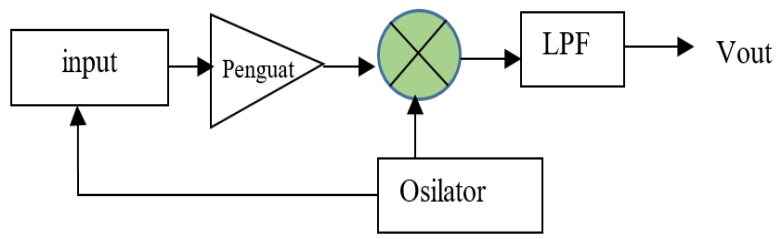

Gambar 1. Diagram blok penguat lock-in.

Apabila dimisalkan sinyal keluaran dari input adalah sinusoidal, maka pada keluaran penguat berlaku persamaan:

$$
V(t)=V \sin (\omega t+\emptyset)
$$

Sinyal referensi sekaligus sinyal modulasi yang dihasilkan oleh 
osilator berosilasi pada frekuensi tinggi serta memiliki amplitudo yang tetap, dinyatakan sebagai:

$$
V_{R}(t)=\sin (\Omega t)
$$

Pada mixer, sinyal input dikalikan dengan sinyal referensi. Output dari pengalian ini menghasilkan dua frekuensi yang didapat dari penjumlahan dan selisih frekuensi kedua masukan, seperti yang ditunjukkan pada persamaan berikut ini:

$$
V(t) V_{R}(t)=\frac{V}{2}\{\cos [(\omega-\Omega) t+\emptyset]-\cos [(\omega+\Omega) t+\emptyset]\}
$$

Jika $\Omega=\omega$ maka didapatkan output berupa sinyal sinus yang memiliki offset DC, dinyatakan:

$$
V(t) V_{R}(t)=\frac{V}{2}\{\cos [\varnothing]-\cos [2 \Omega t+\varnothing]\}, \omega=\Omega
$$

Jika sinyal tersebut dilewatkan ke low pass filter (LPF) maka akan diperoleh:

$$
V_{\text {out }}=V \cdot \cos (\varnothing)
$$

Jika sinyal terganggu dengan derau, maka keluaran dari pengali ditunjukkan pada persamaan berikut:

$V(t) V_{R}(t)=\frac{1}{2} V(t) \cos \phi+\frac{1}{2} V(t) \cos (2 \omega t+\phi)+n(t) \cos (\omega t+\phi)$ Jika pada persamaan tersebut diterapkan LPF dengan frekuensi cut-off lebih kecil dari $\omega / 2$ maka sinyal komponen derau akan hilang [7].

\section{PERANCANGAN SISTEM}

\section{A. Diagram Blok Sistem}

Pada Gambar 2 dapat dilihat bahwa sistem bekerja diawali dengan penguatan sinyal sensor gas yang sangat kecil. Penguatan ini bertujuan agar sinyal sensor gas dapat dibaca oleh arduino. Pada waktu yang sama, arduino juga membangkitkan sinyal kotak yang kemudian menjadi sinyal modulasi untuk sensor dan menjadi sinyal referensi untuk proses perkalian sinyal. Data sinyal yang telah dibaca oleh arduino kemudian dikirim secara serial ke komputer. Data tersebut kemudian akan dikalikan dengan sinyal referensi. Output dari pengali (mixer) kemudian disaring menggunakan LPF.

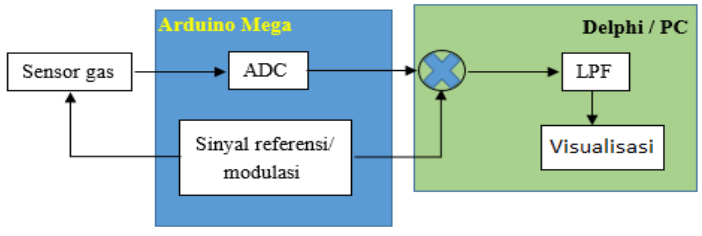

Gambar 2. Diagram blok perancangan sistem penguat lock-in digital.

\section{B. Perangkat Keras}

Perangkat keras terdiri dari modul rangkaian sensor, rangkaian osilator, Arduino dan komputer. Sensor gas yang digunakan merupakan sensor gas tipe MQ-7 yang berfungsi untuk mendeteksi kadar gas karbon monoksida di udara. Tegangan suplai yang harus diberikan ke sensor adalah $5 \mathrm{~V}$ yang termodulasi, sedangkan tegangan heater $(\mathrm{Vh})$ diberikan 5V DC. Perancangan rangkaian sensor ditunjukkan pada Gambar 3.

Perancangan rangkaian osilator dilakukan untuk menguji sistem penguat lock-in sebelum sistem tersebut diimplementasikan pada sensor gas MQ-7. Rangkaian dari osilator ditunjukkan pada Gambar 4. Komponen yang digunakan untuk membuat osilator adalah IC timer LM555 yang keluarannya kemudian dimodulasi dengan sinyal referensi. Pembangkit sinyal yang dirancang memiliki keluaran dengan frekuensi $1.4 \mathrm{~Hz}$.

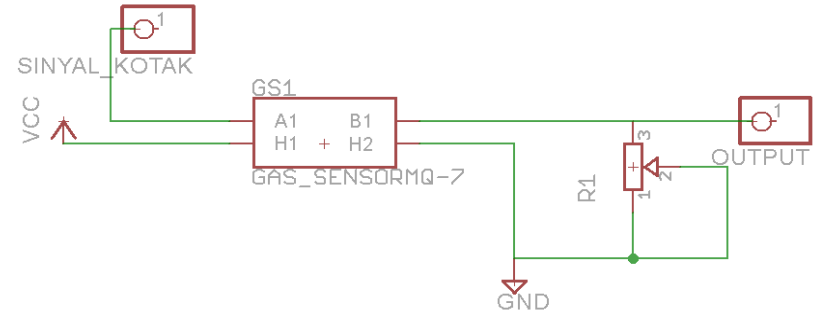

Gambar 3. Rangkaian gas sensor MQ-7.

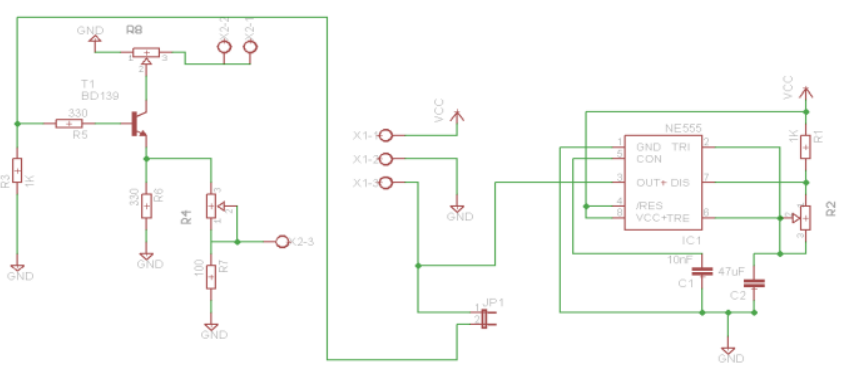

Gambar 4. Rangkaian osilator menggunakan timer 555.

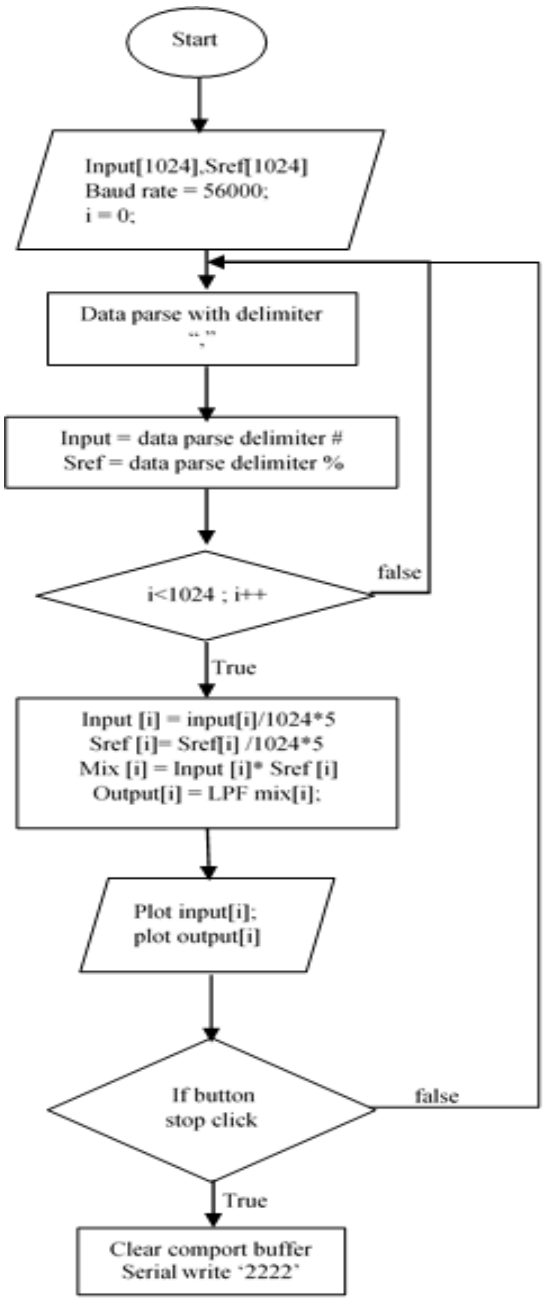

Gambar 5. Diagram alur program penguat lock-in digital pada komputer.

\section{Perangkat Lunak}

Perancangan perangkat lunak terbagi menjadi dua yaitu, perangkat pada arduino dan perangkat lunak pada komputer. Pada perangkat lunak arduino terdiri dari pembacaan ADC dan pembangkitan sinyal kotak yang digunakan sebagai sinyal referensi. Perancangan perangkat lunak pada komputer meliputi 
semua komponen dari penguat lock-in yang terdiri dari mixer dan LPF, ditunjukkan pada Gambar 5.

\section{PENGUJIAN DAN ANALISIS}

\section{A. Pengujian Penguat Lock-in untuk Sinyal Kotak LM555}

Pengujian sistem penguat lock-in dilakukan secara real-time terhadap sinyal yang terganggu oleh derau. Pada pengujian awal, sinyal kotak dengan frekuensi $1.2 \mathrm{~Hz}$ dan amplitudo $4.4 \mathrm{~V}$ yang berasal dari rangkaian LM555 digunakan sebagai sinyal input, ditunjukkan pada Gambar 6. Sinyal input tersebut kemudian dimodulasi dengan sinyal $900 \mathrm{~Hz}$ dengan amplitudo $4.8 \mathrm{~V}$ yang dihasilkan oleh arduino. Hasil dari modulasi kemudian dilewatkan ke pembagi tegangan untuk mendapatkan derau pada sinyal tersebut, ditunjukkan pada Gambar 7. Dengan menggunakan persamaan (7) diperoleh nilai Signal-to-Noise Ratio (SNR) sebesar -18,95 dB.

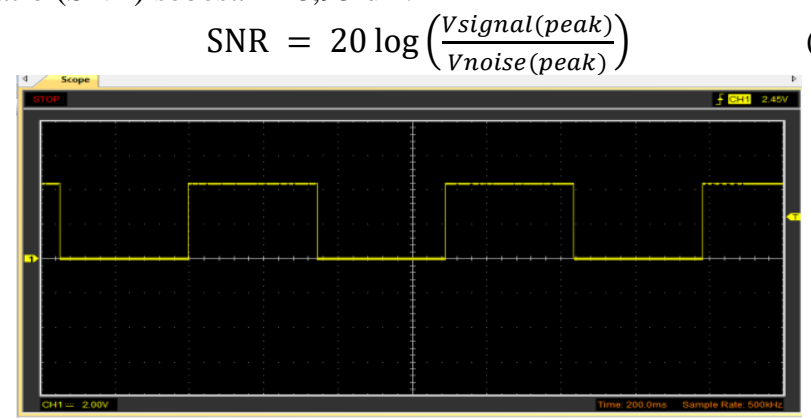

Gambar 6. Sinyal kotak LM555.

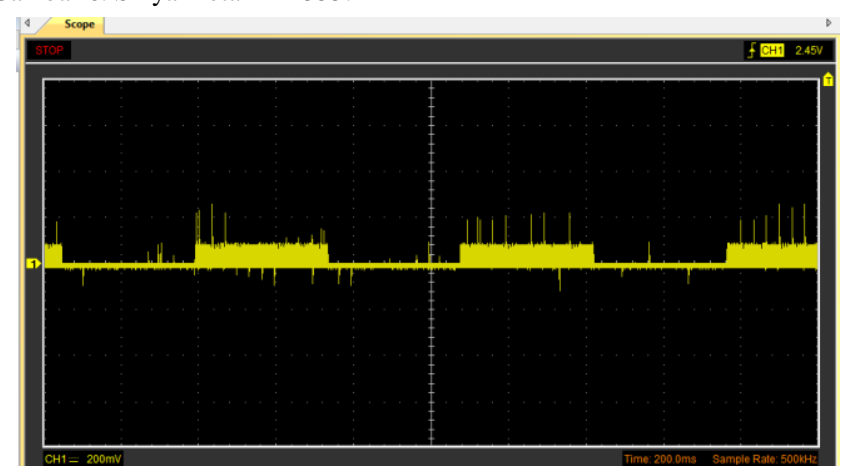

Gambar 7. Sinyal kotak LM555 yang termodulasi setelah melewati pembagi tegangan.

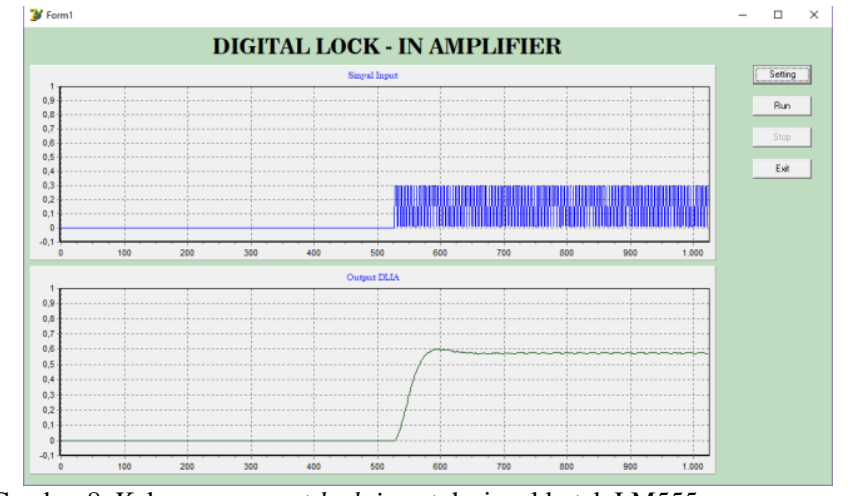

Gambar 8. Keluaran penguat lock-in untuk sinyal kotak LM555.

Sinyal yang telah termodulasi tersebut kemudian dikirim ke komputer untuk diproses dalam penguat lock-in digital, ditunjukkan pada Gambar 8. Dari pengujian yang dilakukan ini, sinyal keluaran penguat lock-in memiliki SNR sebesar 21,23 $\mathrm{dB}$.

\section{B. Pengujian Penguat Lock-in untuk Sensor Gas MQ-7}

Pengujian berikutnya adalah mengimplementasikan sinyal sensor gas MQ-7 pada penguat lock-in. Percobaan diawali dengan mengamati sinyal pada saat belum diberikan gas karbon monoksida pada ruang gas uji yang ditunjukkan pada Gambar 9. Gambar 10 menunjukkan sinyal dari keluaran sensor MQ-7 ketika diberikan gas karbon monoksida dengan volume $1 \mathrm{~mL}$ pada ruang uji gas. Dari pengamatan didapatkan tegangan puncak ke puncak dari sinyal asli dan sinyal noise masingmasing $35 \mathrm{mV}$ dan $11 \mathrm{mV}$, sehingga SNR dari sinyal tersebut adalah $10 \mathrm{~dB}$. Sinyal tersebut kemudian dimodulasi dan diproses pada sistem penguat lock-in dengan frekuensi cut-off LPF sebesar $10 \mathrm{~Hz}$. Keluaran dari penguat lock-in ditunjukkan pada Gambar 11.

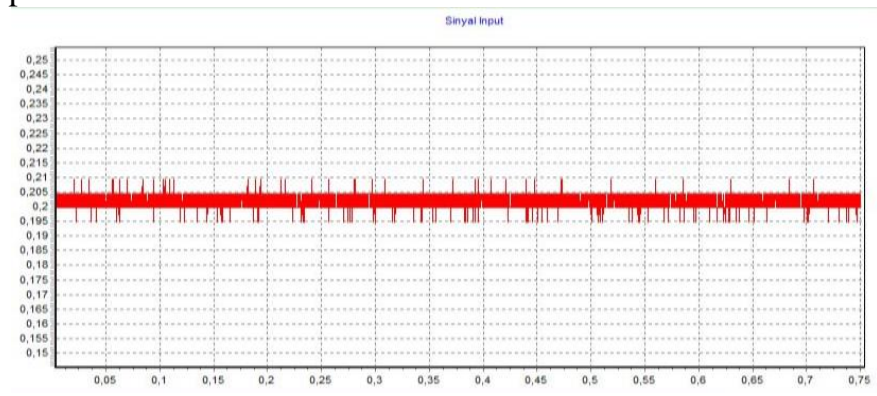

Gambar 9. Sinyal sensor gas MQ-7 tanpa sampel gas.

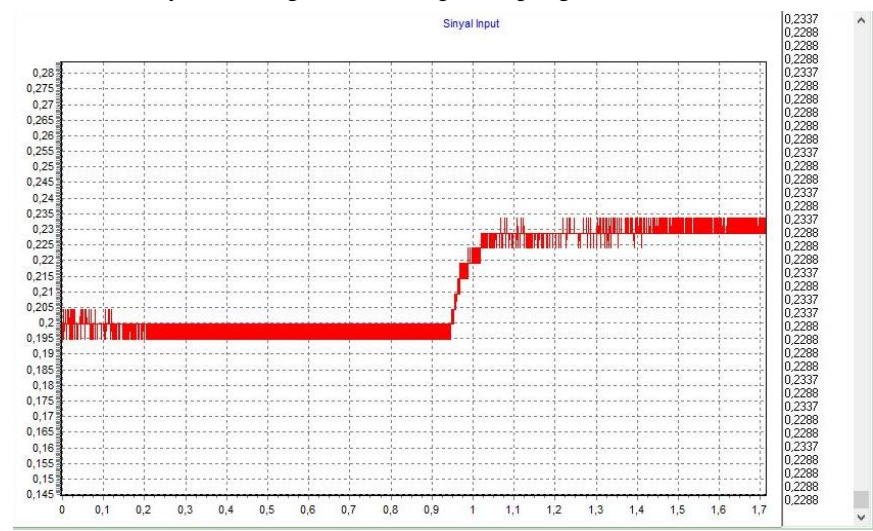

Gambar 10. Sinyal sensor gas MQ-7 dengan sampel gas $1 \mathrm{~mL}$.

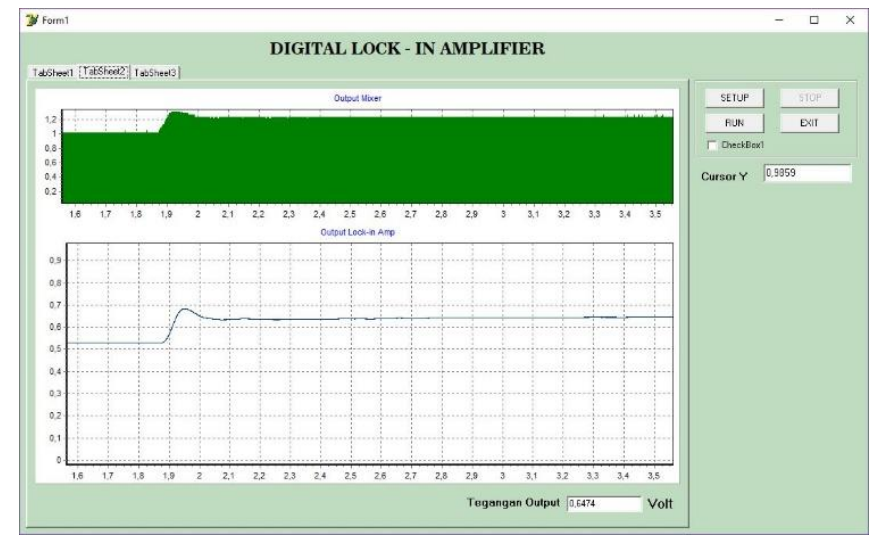

Gambar 11. Keluaran penguat lock-in digital ketika ditambah gas $1 \mathrm{~mL}$.

Dari pengamatan yang telah dilakukan didapatkan tegangan Vpp sinyal asli sebesar $144.7 \mathrm{mV}$ dan Vpp noise sebesar $12 \mathrm{mV}$ sehingga diperoleh nilai SNR sebesar 21,63 dB. Pengujian berikutnya dilakukan dengan menambahkan gas karbon monoksida dengan volume $2 \mathrm{~mL}$ yang ditunjukkan pada Gambar 12. Dari pengamatan dihasilkan nilai Vpp sinyal asli 
adalah 54,1 $\mathrm{mV}$ dan $\mathrm{Vpp}$ dari noise adalah $14,6 \mathrm{mV}$ sehingga diperoleh SNR sebesar 11,38 dB. Gambar 13 menunjukkan keluaran penguat lock-in dengan tegangan Vpp dari sinyal asli adalah $192,5 \mathrm{mV}$ dan tegangan Vpp dari noise adalah 7,5 mV sehingga diperoleh SNR sebesar 28,18 dB.

Percobaan selanjutnya dilakukan dengan menambahkan gas karbon monoksida dengan volume $3 \mathrm{~mL}$ kedalam ruang uji gas, ditunjukkan pada Gambar 14. Tegangan Vpp dari sinyal asli adalah 90,1 $\mathrm{mV}$ dan tegangan Vpp dari noise adalah 9,8 mV sehingga inyal keluaran sensor gas MQ-7 ini memiliki SNR $19,26 \mathrm{~dB}$.
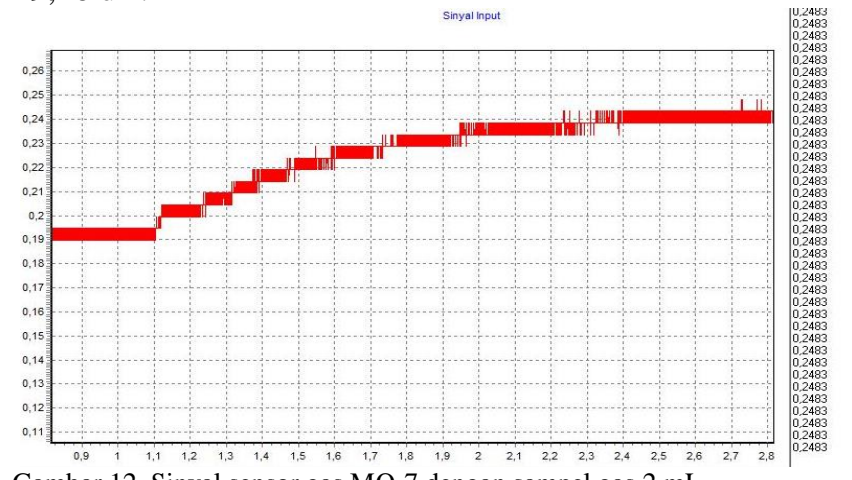

Gambar 12. Sinyal sensor gas MQ-7 dengan sampel gas $2 \mathrm{~mL}$.

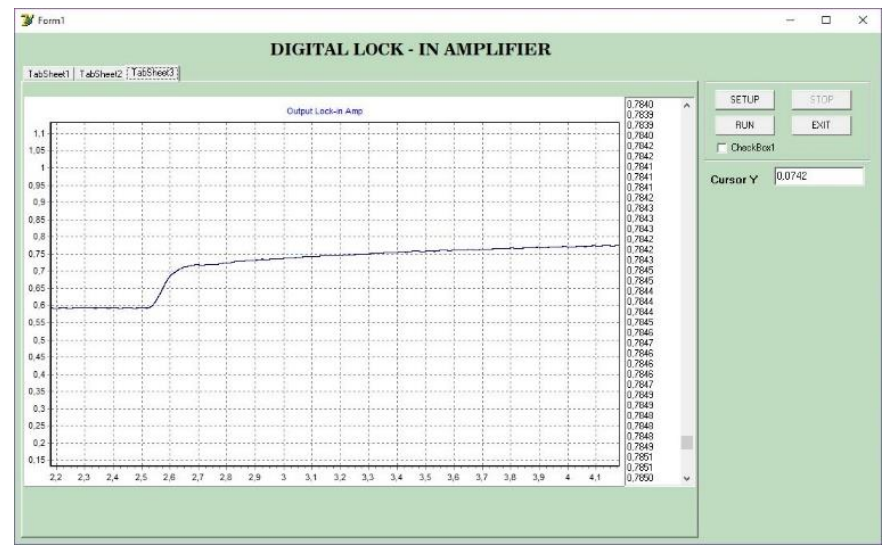

Gambar 13. Keluaran penguat lock-in digital ketika ditambah gas $2 \mathrm{~mL}$.

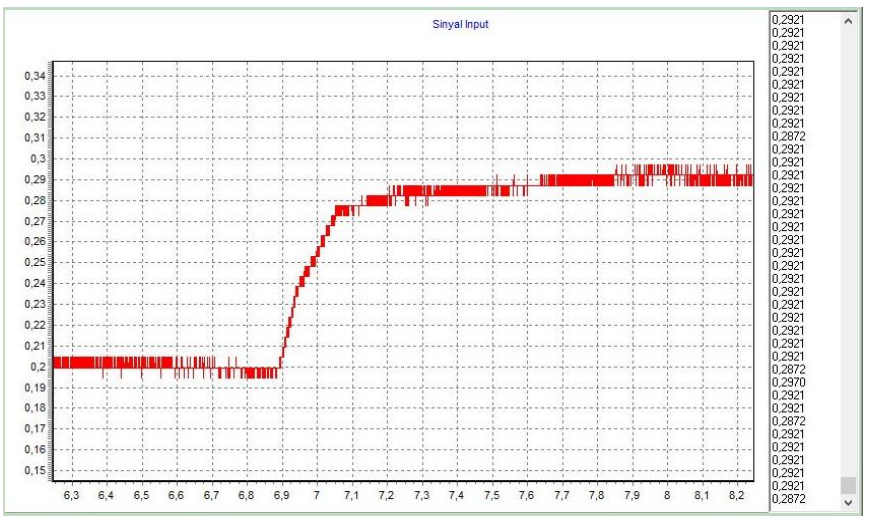

Gambar 14. Sinyal sensor gas MQ-7 dengan sampel gas $3 \mathrm{~mL}$.

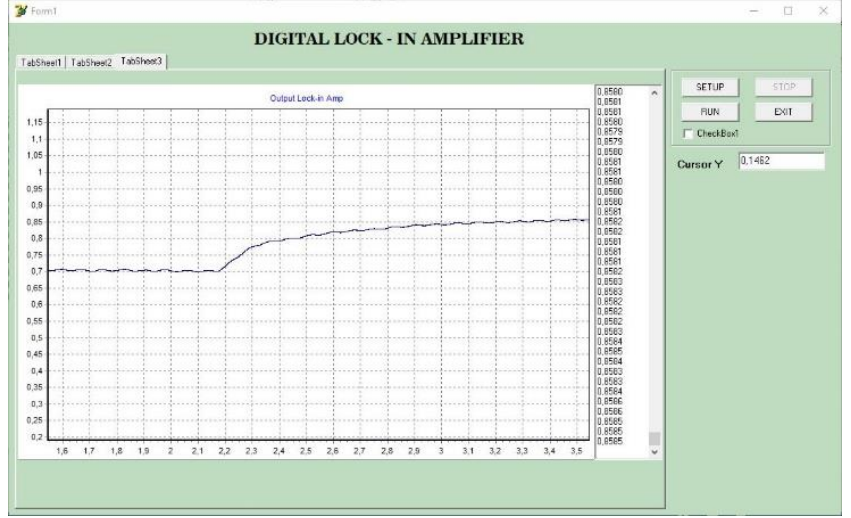

Gambar 15. Keluaran penguat lock-in digital ketika ditambah gas $3 \mathrm{~mL}$.

Tabel 1.

Tabel perbandingan SNR untuk setiap percobaan

\begin{tabular}{lcccc}
\hline \hline \multirow{1}{*}{ Percobaan } & \multirow{2}{*}{$\begin{array}{c}\text { Frekuensi } \\
\text { Input }\end{array}$} & $\begin{array}{c}\text { Frekuensi } \\
\text { cut-off }\end{array}$ & $\begin{array}{c}\text { Tanpa } \\
\text { lock-in }\end{array}$ & $\begin{array}{c}\text { Dengan } \\
\text { lock-in }\end{array}$ \\
\hline $\begin{array}{l}\text { Osilator sebagai } \\
\text { masukan }\end{array}$ & $1,4 \mathrm{~Hz}$ & $50 \mathrm{~Hz}$ & $-18,95 \mathrm{~dB}$ & $27 \mathrm{~dB}$ \\
$\begin{array}{l}\text { MQ-7 (1mL gas } \\
\text { buang) sebagai } \\
\text { masukan sistem }\end{array}$ & - & $10 \mathrm{~Hz}$ & $10 \mathrm{~dB}$ & $21,63 \mathrm{~dB}$ \\
$\begin{array}{l}\text { Sensor MQ-7 } \\
\text { (2mL gas }\end{array}$ & & & & \\
$\begin{array}{l}\text { buang) sebagai } \\
\text { masukan sistem }\end{array}$ & - & $10 \mathrm{~Hz}$ & $11,38 \mathrm{~dB}$ & $28,18 \mathrm{~dB}$ \\
$\begin{array}{l}\text { Sensor MQ-7 } \\
\text { (3mL gas } \\
\text { buang) }\end{array}$ & - & $10 \mathrm{~Hz}$ & $19,26 \mathrm{~dB}$ & $26,24 \mathrm{~dB}$ \\
\hline \hline
\end{tabular}

${ }^{\mathrm{a}} \mathrm{SNR}$ - Signal to Noise ratio.

Gambar 15 merupakan keluaran penguat lock-in digital dengan Vpp dari sinyal asli adalah $153,85 \mathrm{mV}$ dan Vpp dari noise adalah 7,5 $\mathrm{mV}$ sehingga menghasilkan SNR sebesar $26,24 \mathrm{~dB}$.

Tabel 1 menunjukkan hasil pengukuran SNR untuk semua percobaan yang telah dilakukan. Dari data tersebut dapat disimpulkan bahwa penguat lock-in digital mampu menaikkan nilai rerata SNR pada sinyal yang berasal dari sensor gas sebesar $12 \mathrm{~dB}$.

\section{KESIMPULAN}

Pada penelitian ini telah dibuat sebuah sistem penguat lockin digital yang terdiri dari sensor gas MQ-7, mikrokontroler Arduino Mega 2560, dan personal komputer. Sinyal pemodulasi mempunyai frekuensi $900 \mathrm{~Hz}$. Rangkaian LPF mempunyai cut-off frequency sebesar $10 \mathrm{~Hz}$. Hasil percobaan yang menggunakan sampel gas $\mathrm{CO}$ menunjukkan bahwa penguat lock-in digital mampu menaikkan nilai rerata SNR pada sinyal yang berasal dari sensor gas sebesar $12 \mathrm{~dB}$. Hal ini membuktikan bahwa penguat lock-in digital yang telah dibuat dapat memperbaiki kualitas sinyal yang berasal dari sensor gas. 


\section{DAFTAR PUSTAKA}

[1] Ballarà G, Advisor M, Miguel J and Lopez A Lock-In Amplifier based on Virtual Instrumentation

[2] Anon The Benefits of DSP Lock-in Amplifiers (Application Note A12)

[3] Anon Teledeteksi Gas pada Mobile Robot yang Dikendalikan Gelombang Radio

[4] Priyanta I F, Rivai M and Dikairono R 2016 Pemetaan Distribusi Gas Polutan Menggunakan Quadcopter Berbasis Autonomous Waypoint Navigation J. Tek. ITS 5 A154-9

[5] Akbar L A and Rivai M 2016 Rancang Bangun Sensor Node pada Wireless Sensor Network Menggunakan Deret Sensor Gas dan Jaringan Syaraf Tiruan untuk Mendeteksi Kebakaran Hutan J. Tek. ITS 5 A192-7

[6] Supeno B A, Rivai M and Budiman F 2017 Rancang Bangun Data Logging Berbasis Web Server Pada Robot Balon Udara Untuk Deteksi Kebocoran Pipa Gas J. Tek. ITS 5

[7] Rahmannuri H, Rivai M and Sardjono T A 2017 Design of Digital Lockin amplifier for Low Concentration Gas Detection 2017 International Seminar on Intelligent Technology and Its Applications (ISITIA) (IEEE) pp 319-22 